\title{
ACTIVE LEARNING METHODS IN STUDIES: STUDENTS’ OPINIONS AND EXPERIENCES
}

\author{
Agita Smitina \\ Vidzeme University of Applied Sciences, Latvia \\ Ieva Margevica-Grinberga \\ University of Latvia, Latvia
}

\begin{abstract}
Rapid changes in education and pedagogy are related not only to the global crisis caused by COVID-19, but also to other changes determined by globalization and technological convergence-labour mobility, changes in different professions and changes in teacher-student relations - that are also affected by intergenerational differences. Changes in the pedagogical paradigm, which are included in the content of the Paris Communiqué (2018) and outlined in many important educational development and planning documents, emphasise students' transition from being mere recipients of information to being participants actively engaged with new information in a learning environment. Following the identification of problems with a less frequent use of active participation methods in higher education, the University of Latvia implemented an Erasmus + project entitled Entrance to Future Education (2017-2019). In this project, the authors summarized modern, inspiring, interactive, active engagement-oriented teaching/learning methods in higher education. During the project, several student focus groups were formed to discuss students' experiences with active engagement methods in studies, and a handbook with various student active engagement methods and games was created. In 2020, 106 students from different Latvian universities were surveyed about their understanding and experience in relation to these teaching methods in their studies. The results showed that, according to students, attitude and ardour are essential for engaging students with enthusiasm and interest in the study process. The results of the survey show the varied experiences of students, as well as different understandings of active learning methods. Students noted that they most often experienced various group projects in studies, presentations and various tasks outside the classroom, but relatively rarely used such methods as creative video making, active use of game elements and constructive feedback from peers.
\end{abstract}

Keywords: Active learning, Active learning methods, Learning environment, Student-centred learning.

\section{Introduction}

Changes in the pedagogical paradigm of higher education are inconceivable without a change from a teacher-centred to a student-centred approach in the learning process. Principles of the student-centred approach are not only included in most important educational documents (Paris Communiqué, 2018; European 
University Association, 2019; Standards and Guidelines for Quality Assurance in the European Higher Education Area, 2015), but are also an important factor in different teaching techniques to provide students with interesting and exciting learning in their studies. This approach is used at a time when the COVID-19 crisis has transformed the learning process such that schools have almost entirely switched to a distant learning style. According to the analysis provided by the report of the European Students' Union's Bologna with Student Eyes 2018 (ESU, 2018), student-centred learning (SCL) is also an objective measure of quality among higher education institutions. Most findings provide evidence that teachers who use some elements of SCL saw students who were actively engaged in the learning process, were more aware of their responsibility and sense of autonomy, and learned from their own experience (Kok, 2014). Although the student-centred approach has been relevant for many years, many universities and faculty still face various challenges in reorienting their learning process in line with this approach (Sadler, 2012). Teachers have described challenges in putting this way of thinking into practice and lack innovative methods to engage students more fully in the learning process (Sadler, 2012). The ESU study also pointed out that quantitative data still show the problems in implementing this aspect (ESU, 2018). To promote the pedagogical competence of high-school teachers with regard to student-centred teaching and to give them practical tools to work with students, several universities from Latvia, Poland and Belgium jointly developed the project Entrance to future education (http://efe-project.eu/).

The current study was conducted with the aim of exploring students' experiences with active (engaging) methods in the study process in higher education. Specifically, the research questions governing the current study were:

1) What is the students' experience with active teaching/learning methods in the study process?

2) How often in the study process do students come into contact with active, engaging, motivating, student-centred study methods?

3) What are the students' recommendations for the improvement of the study process?

\section{Student-centred Approach in Higher Education}

The rapid development of research on a student-centred approach to learning began in the 1990s and 2000s (Burnard, 1999; Taylor, 2000; Bayeten \& Kyndt, 2010; McCabe, 2014). The student-centred approach stipulates that education provision in all its aspects is defined by the intended learning outcomes and most suitable learning process, instead of the student's learning being determined by the education provided (EUA, 2018). In the context of the Bologna Process, student-centred learning is defined as "an approach that replaces transmissive 
models of education with an outcome-based perspective implemented through 'new approaches to teaching and learning, effective support and guidance structures and a curriculum focused more clearly on the learner'” (EHEA, 2009, p. 3). Students should take an active role in creating the learning process and responsibility for their own success and progress in the study process; so they could better benefit their personal learning and the quality of education for their institution (ESU, 2015).

Although a student-centred approach encourages students to have more responsibility for their learning and studies, researchers also emphasise the important role of lecturers and their differing understanding of the learning process, which highlights implications for ongoing practice (McCabe \& O'Connor, 2014). The teacher's position is defined as that of facilitator, whose role is to guide students in taking ownership of their own learning; however, teachers cannot always take this role for the duration of the class, and they often lack different engagement methods (Christersson et al., 2019). The relationship between teacher-centred and SCL environments from the student's perspective has also been researched. Two different views of this relationship were found: the transactional view stresses the continuous renegotiation of educator and student roles, and the independent view emphasises student-centredness as independent features of learning environments (Elen et al., 2007).

\section{Active Learning and Engaging Methods in Studies}

Active learning is the process of involving all students in activities that encourage them to develop a deeper understanding of content by working with and reflecting upon the material being presented (EUA, 2019). Pedagogical methods have developed especially rapidly in recent years, with particular attention paid to active student involvement methods. These methods are often characterised by small group work, with a mix of various creative methods (Sursock \& Smidt, 2010). Games, storytelling, short lectures, simulations, roleplaying, incident process, portfolio development, visualisation, flipping classrooms, gamification, crossover learning, computational thinking, dialogic teaching and problem-based learning (PBL) have been described by several pedagogy researchers (Panke \& Stephens, 2018; Heaysman, 2019). Also, different technology-embedded teaching/learning methods, e.g., blogging, podcasts, quizzes, tasks and interactive idea boards, are recommended as very effective for student active engagement in the learning process (Khairnar, 2015). These methods are particularly useful today, as all in-class processes have been paralysed by the COVID-19 crisis.

Some important factors that influence students' engagement in the process of student-centred learning include sharing of experiences, positive relationships 
with teachers and peer support (Chang, 2013). Previous studies also explored a positive correlation between teachers' educational, social and technological competency and their innovative teaching performance (Chang, 2013).

Several studies showed that students rated their own innovation competence as moderately high (Ovbiagbonhia et al., 2019). However, some also pointed out students' resistance to active learning; they described a variety of strategies to reduce student resistance, including several successful ways to implement the strategies (Tharail et al., 2018).

Still, some concerns regarding assessment methodologies remain. Assessments using SCL methods should include formative and regular feedback to allow both teacher and student to closely monitor the learning progress and reflect on it. Assessment should be defined through intended learning outcomes (EUA, 2018).

\section{Innovative Active Learning Methods in the Project Entrance to Future Education}

From 2017-2019, the Career Development Centre, University of Latvia (Latvia), in cooperation with partners from UC Leuven-Limburg (Belgium), Media \& Learning Association (Belgium) and Humanitarian and Economic University in Lodz (Poland), initiated the Erasmus+ project, Entrance to future education, with the aim of highlighting teaching methods that activate, motivate, inspire and excite students and help them to develop the skills required in the 21st century labour market.

Forty different active learning methods have been tried and summarised in methodological material entitled Student-centred Teaching Methods for the Development of 21st Century Skills, developed based on research and focus group discussions with students and academics.

The methods were divided into two bigger groups: strategic approach and techniques/methods (see examples in Table 1).

The strategic approach included design thinking, which provides a solutionbased approach; it is a way of thinking and working as well as a collection of hands-on methods. Peer assessment or peer review provides a structured learning process for students to critique and provide feedback to each other on their work and can comprise distinctive techniques. Techniques and methods are more concrete and could be used in different stages of learning. 
Table 1 Examples of Active Learning (AL) Methods in the EFE Project

\begin{tabular}{cl}
\hline Strategic Approach & Techniques/Methods \\
\hline Design thinking & Virtual exhibition \\
Creative project & Think-aloud-pair-share \\
Art-based scenario writing & Knowledge clips \\
Play projects & Documentary making \\
Flipped classroom & Clustering \\
Lecture capture & What? So what? Now what? \\
Peer assessment & Tell and sell \\
Video assessment & Genealogy of an idea \\
Virtual internship & 3-2-1 processor \\
& Translate it!
\end{tabular}

\section{Methodology}

The authors performed during the project a qualitative study using 5 focus group discussions with students from University of Latvia. Focus groups with students were organized during the period from March to October. Focus group discussion sessions lasted for 54 (median) minutes. Focus group discussions were transcribed; the coding of all categories were performed according to themes that relate to the research questions (Which methods do students consider modern and innovative? What is the students' experience in using modern teaching/learning methods in the study process?). To address these study aims and research questions, quantitative data was collected through online questionnaires from a sample of 106 randomly selected students representing 18 different study programmes, including Management, Communication and Public Relations, Cyber Security and Programming, Psychology, Teacher Education, etc. from the University of Latvia, Vidzeme University of Applied Sciences, Riga Technical University, Riga Stradins University, Liepaja University, Ventspils University of Applied Sciences and Daugavpils University. Although type I error can never be avoided entirely, the investigator can reduce its likelihood by increasing the sample size (the larger the sample, the lesser the likelihood that it will differ substantially from the population) (Banerjee et al., 2009). The online questionnaire included different statements on students' assessment of the usefulness of the relevant teaching method in the study process and also of student's experience of the following methods. The teaching/learning methods were chosen from the EFE Manual for Academic Teaching Staff. Statements of opinion were evaluated on a 5-point Likert scale. Data was analysed through descriptive statistics - measures of frequency—in Microsoft Excel since the data was categorical in nature. 
Smitina \& Margevica-Grinberga, 2021. Active Learning Methods in Studies: Students' Opinions and Experiences

\section{Findings and Discussion}

The majority of the survey participants considered the use of creative communication methods in group work very useful (52\%) (see Figure 1). An explanation for this distribution of preference can be found in the focus groups, where it was emphasized that group work is often present in each lesson and, in the students' opinion, is sometimes organized because of the method per se rather than to reach the goal.

Additionally, 59\%, 34\%, 4\%, and 3\% of the students considered creative methods for working together online (brainstorming, brainstorming tools, question games and other interactive tools) very useful, useful, somewhat useful, and not useful, respectively.

In the focus group discussion, some students indicated that their expectations are to be active participants in the study process. For example, one of the respondent comments about the study process: "I and my course mates appreciate the methods used in the study process that lead to a creative path, such as searching for scientific answers to conflicting information, working with other classmates in a team, creating products or prototypes that can benefit society". The majority of respondents, totalling 58\%, considered discussions and debates in small groups to be very useful, while $2 \%$ either considered the method not to be useful or did not know about it.

Peer review of classmates' work was considered to be either useful or somewhat useful by the majority of the students (33\%), while creating videos, actively using multimedia, video production and active use of other multimedia was considered to be useful by most of the respondents (31\%). In addition, 31\%, $34 \%, 27 \%$ and $5 \%$ of the respondents considered creating joint presentations to be very useful, useful, somewhat useful and not useful, respectively, while $3 \%$ of the respondents did not know about this method.

The majority of the respondents considered study tours (37\%) and case simulation, case-study situation simulation and case solving to be very useful (65\%). Most of the students considered common study tasks and joint study tasks outside the classroom (39\%) and the use of game elements (badges, prizes, and competition elements) to be a useful method of learning (see Table 1 below).

The results obtained in both the focus group discussion and the questionnaire reveal that students prefer active, interactive teaching and learning methods, which require active engagement, responsibility, problem-solving, decisionmaking, and self-assessment. The results are also in line with the active learning methods indicated in the literature (e.g., Nicolaides, 2012), such as the use of different types of games and their elements. 


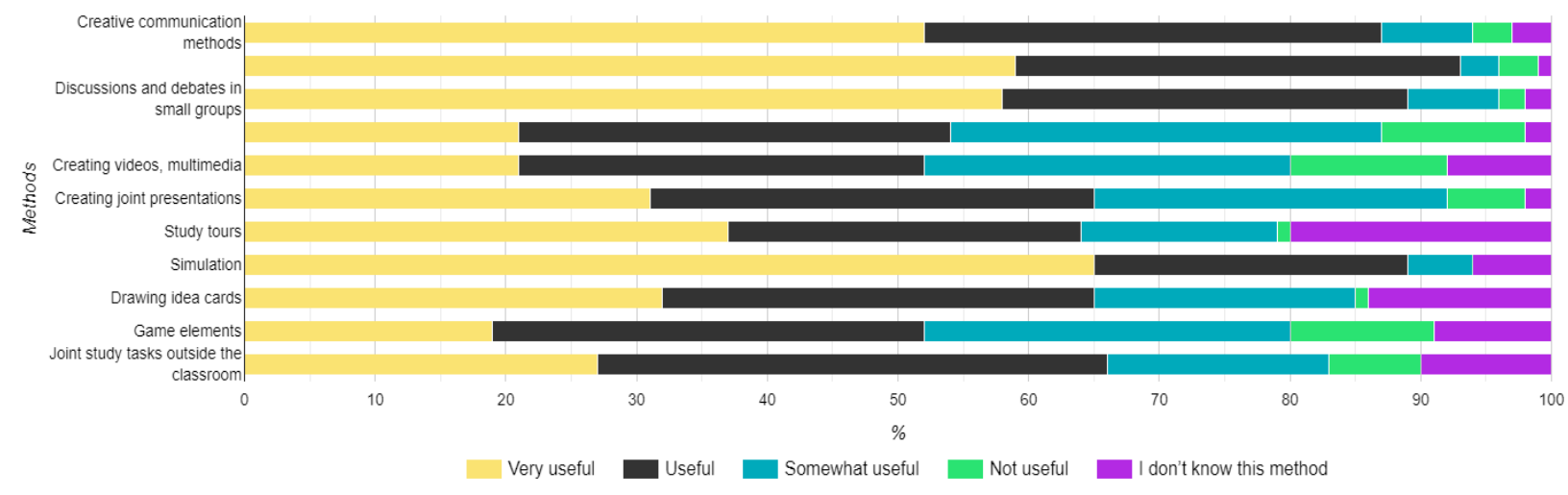

Figure 1 Summary Statistics of Student's Opinion about AL Method's Usefulness in Promoting Greater Student Involvement and Interest in Studies, \% $(n=98)$

In the analysis of students' experience based on the frequency of methods used by their teachers (see Figure 2), the most frequently (very often) used student engagement method used by teachers was discussions and debates in small groups (32\%). The involvement methods that students never or very rarely experienced in their studies were creating videos, actively use of other multimedia video production and active use of other multimedia (48\%). It should be noted that also drawing idea cards (30\%) most of the teachers rarely preferred use in teaching. Creative communication methods also are not so commonly used in group work only $31 \%$ of students noted that their teachers use these methods often or very often. In addition, $6 \%, 24 \%, 26 \%, 35 \%$ and $9 \%$ of the teachers never, rarely, sometimes, often and very often (respectively) engaged students in creative methods for working together online. Peer review of classmates' work was sometimes used by the majority of the teachers as an involvement method (32\%), while creating joint presentations was used often (37\%). Common study tasks and joint study tasks outside the classroom were sometimes (29\%) used, while the use of game elements (badges, prizes, and competition elements) students were never (46\%) experienced.

These results highlight a perceived contradiction between what a student appreciates as an interesting and exciting method and what they experience in their everyday studies as well as in-class learning as well in digital learning process. 
Smitina \& Margevica-Grinberga, 2021. Active Learning Methods in Studies: Students' Opinions and Experiences

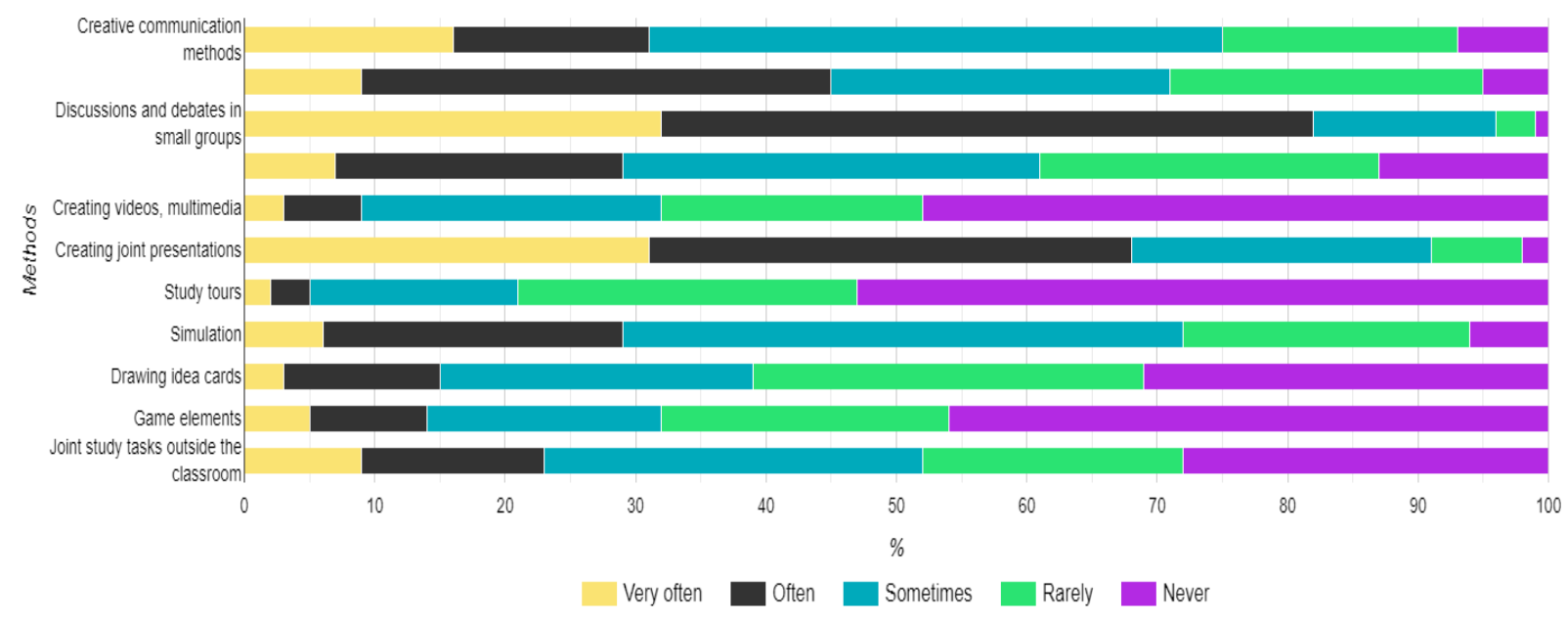

Figure 2 Summary Statistics of Students' Experience in Studies \% (n=98)

Summarizing the obtained results, it can be seen that several active learning methods, such as creative methods, teaching tours or simulation methods, are evaluated as very useful and usable, but students experience much less in their learning process. However, the qualitative data of the focus groups reveal that students value teachers' interest and passion for subject, the ability to balance theoretical and practical knowledge, practical tasks related to real life and learning new experiences. Here is student's comment "Would love to go to an institution, or even to the market, for example, to observe, interview clients and sellers. Then, together with the group members, I would perform an analysis, connect with the theory, and come to the lecture with my presentation. I had to do something practical rather than just sitting in a lecture." Students in focus groups also raised an important issue regarding digital tools that academic staff might use to encourage students to engage in the study process and provide immediate feedback. Some students expressed their opinion as follows: "Introducing an electronic system for students' questions, e.g., Sli.do - a lecturer is talking, and students' questions appear on the screen, and afterwards, the teacher answers the questions or students discuss them. I immediately see a lively discussion. Even passive students ask questions. Using the tools, they can anonymously post questions from phones and vote on questions they like. Because often students forget that their words have power." The fact that students appreciate various creative active learning methods is already confirmed by literature sources (Panke \& Stephens, 2018; Heaysman, 2019), as well as showing both the results of the questionnaire and the comments of the focus group, such as "I like creative work. To draw, to make. For example, we had to choose a topic and make a social advertisement. We wrote about the air in schools." or "I like: 1. compulsory practice, 2. creative exercises, 3. a lot of practical work." Students also appreciate 
the teacher's enthusiasm in teaching process and the attitude towards students: "It is important that the teacher is interested in working with every student." "Lecturer is welcoming the students with the attitude - "Wow, students!" Everyone could recall one lecturer who came to the first lecture, sat down on the table and showed Star Wars and Harry Potter". These comments also confirm the teacher's position as facilitator, whose role is to guide students in taking ownership of their own learning (Christersson et al., 2019).

\section{Conclusions}

Adoption of active learning by students in higher education allows the students to develop multiple skills and practices. Active learning has been advocated for by the majority of educators across the different countries not only because students are able to learn and reflect on their own experiences but also because they are able to achieve academic excellence with meaningful learning. Based on the data analysis conducted above, it is clear that simulation, case-study situation simulation, and case solving (case-study) are the most (very) useful involvement methods, while discussions and debates in small groups are the most frequently used student involvement methods among students of higher learning. Since the sample size was large enough $(n \geq 30)$ and proper data analysis techniques were employed, the study results were considered to be statistically valid.

The obtained research data reveal that higher education institutions should pay particular attention to the contradiction between students' expectations regarding the study process and what they experience in reality. The results of the research indicate the need to diversify the teaching methods used, paying attention to the inclusion of simulations, games and creative work in the study process.

It have concluded that students as innovative and engaging methods mostly recognize those methods that allow them to take responsibility for constructing their knowledge, be creative and actively cooperate with peers. The study shows that a positive study environment in which high quality learning can be "experienced" is essential. Students believe that learning should not be limited to university walls, but should go beyond them, using the opportunity to explore real world problems where they occur. The study reveals a positive trend that academics want to learn new teaching methods and implement them in a study process. 
Smitina \& Margevica-Grinberga, 2021. Active Learning Methods in Studies: Students'

Opinions and Experiences

\section{References}

Banerjee, A., Chitnis, U. B., Jadhav, S. L., Bhawalkar, J. S., Chaudhury, S. (2009). Hypothesis testing, type I and type II errors. Industrial Psychiatry Journal, 2009 Jul-Dec, 18(2), 127131. Retrieved from https://www.ncbi.nlm.nih.gov/pmc/articles/PMC2996198/

Christersson, C., Staaf, P., Zhang, T. and Peterbauer, H. (2019). Promoting active learning in universities: Thematic Peer Group Report. Learning \& Teaching Paper \#5 (Brussels, EUA). Retrieved from http://bit.ly/EUATPGr5

Chang, Zh. (2013). What core competencies are related to teachers' innovative teaching. AsiaPacific Journal of Teacher Education, 41(1), 9-27.

EHEA. (2009). Leuven and Louvain-la-Neuve Communiqué. Retrieved from http://bit.ly/ 2JI2znt

Elen, J., Clarebout, G., Leonard, R., Lowyck, J. (2007). Student-centred and teacher-centred learning environments: what students think. Teaching in Higher Education. Vol 12, Issue 1. DOI: https://doi.org/10.1080/13562510601102339

European Commission. (2018). European Commission /EACEA/Eurydice (2018). The European Higher Education Area in 2018: Bologna Process Implementation Report. Luxembourg, Publications Office of the European Union. Retrieved from http://bit.ly/2u785Z9

European University Association. (2019). Student-centred learning: approaches to quality assurance. Retrieved from https://eua.eu/downloads/publications/student-centred\% 20learning_approaches\%20to\%20quality\%20assurance\%20report.pdf

European Students' Union (ESU). (2015). Overview on Student-Centred Learning in Higher Education in Europe: Research Study. Retrieved from http://bit.ly/2HumqGW

European Students' Union (ESU). (2018). Bologna with Student Eyes: The Final Countdown. Retrieved from http://bit.ly/2Hm9QKB

Entrance to future education (EFE). (2019). Innovative Teaching in HE. Retrieved from http://efe-project.eu/

Heaysman, O. (2019). Content teaching: innovative and traditional practices. Journal of Educational Studies, 45(3), 342-356.

Kok, L.E. (2014). Investigating Teachers' Views of Student-Centred Learning Approach. International Education Studies, Vol 7, N7, p143-148.

Khairnar, C.M. (2015). Advance pedagogy: Innovative methods of teaching and learning. International Journal of Information and Education Technology, 5(11), 870-873.

McCabe, O'Connor, U. (2014). A. Student-centred learning: the role and responsibility of the lecturer. Teaching in Higher Education, Vol 19, Issue 4. DOI https://doi.org/ 10.1080/13562517.2013.860111

Ovbiagbonhia, A.R., Kolloffel, B., den Brok, P. (2019). Educating for innovation: Students' perceptions of the learning environment and of their own innovation competence. Learning Environments Research, 22, 387-407.

Panke, S., Stephens, J. (2018). Beyond the Echo Chamber: Pedagogical Tools for Civic Engagement Discourse and Reflection. Educational Technology \& Society. Vol. 21, No.1 (January 2018), pp. 248-263.

Paris Communiqué. (2018). Retrieved from http://ehea.info/media.ehea.info/file/2018_ Paris/77/1/EHEAParis2018_Communique_final_952771.pdf

European Higher Education Area. (2015). Standards and Guidelines for Quality Assurance in the European Higher Education Area (ESG). Retrieved from https://www.eqar.eu/kb/esg/ 
Stebbins, R. (2001). Exploratory research in the social sciences: what is exploration? SAGE Publications. Retrieved from https://www.researchgate.net/publication/309967516_ Exploratory_research_in_the_social_sciences_what_is_exploration

Sursock, A. and Smidt, H. (2010). A decade of change in European Higher Education. (Brussels, EUA). Retrieved from http://bit.ly/2NHoVKS

Sadler, I. (2012). The challenges for new academics in adopting student-centred approaches to teaching. Studies in Higher Education, Vol 37, 2012, 731-745.

Tharayil, S., Borrego, M., Prince, M., Nguyen, K., Shekhar, P., Finelli, C. (2018). Strategies to mitigate student resistance to active learning. International Journal of Stem Education, Issue 5, Vol. 7. 